\title{
PRINCIPAIS MÉTODOS DIAGNÓSTICOS DA COVID-19: recomendações e perspectivas
}

\author{
MAIN COVID-19 DIAGNOSTIC METHODS: recommendations and perspectives \\ COVID-19 PRINCIPALES MÉTODOS DE DIAGNÓSTICO: recomendaciones y perspectivas
}

DESCRITORES: COVID-19; Coronavírus; Pandemia; Diagnóstico.

DESCRIPTORS: COVID-19; Coronavirus; Pandemic; Diagnostic.

DESCRIPTORES: COVID-19; Coronavirus; Pandemia; Diagnostico.

RECEBIDO EM: 29/04/2020 APROVADO EM: 30/04/2020

\section{Luciana da Costa Nogueira Cerqueira}

Enfermeira. Mestre em Biociência. Doutoranda em biociência da Universidade Federal do Estado do Rio de Janeiro. Docente do curso de graduação em Enfermagem da Universidade Veiga de Almeida-Campus Cabo Frio. https://orcid.org/0000-0003$1339-6828$

\section{Karina Rangel da Silva Garcia}

Enfermeira. Especialista em neonatologia. Mestranda pela Universidade Federal Fluminense. https://orcid. org/0000.0001.5392.9102

\section{Fernanda Cardoso Trugilho}

Enfermeira pela Universidade Veiga de Almeida. https://orcid.org/0000.0003.2248.9233

\section{Anderson Wilnes Simas Pereira}

Médico. Especialista em Clínica Médica e Cardiologia. Mestre em Ciências Cardiovasculares. Membro Titular da Academia de Medicina do Estado do Rio de janeiro. Coordenador Médico do Centro de Atendimento ao Diabético e Hipertenso - Cabo Frio. https://orcid.org/0000-0002-3736-169X

\section{Bruno Wilnes Simas Pereira}

Acadêmico de Medicina da Universidade Federal de Minas Gerais (UFMG). https://orcid.org/0000-0002-6317-7538

\section{Rafael Messias Gandra}

Enfermeiro. Mestre em Bioquímica. Doutor em Bioquímica. Pós-doutorando do Departamento de Microbiologia e Imunologia na Universidade do Estado de Nova York em Stony Brook. https://orcid.org/0000-0001-7510-6051

\section{Giselle Barcellos Oliveira Koeppe}

Enfermeira. Mestre e Doutora em Enfermagem. Professora do curso de graduação em Enfermagem da Universidade Veiga de Almeida-Campus Cabo Frio. https://orcid.org/0000-0002-4821-1021

$\mathbf{R}$ ecentemente, o mundo foi surpreendido pelo surgimento de uma nova doença, intitulada COVID-19 (Coronavirus Disease-2019), originada da infecção por um tipo de coronavírus, a SARS-CoV-2. Essa nova patologia infecciosa foi identificada em dezembro de 2019, quando um surto de pneumonias, de causas desconhecidas na época, propagou-se em Wuhan, na China, uma cidade densamente habitada, colocando toda a sua população em risco devido ao rápido contágio e disseminação da doença. Após o surgimento de casos em diversos países, a Organização Mundial de Saúde (OMS) se posicionou e declarou a COVID-19 uma pandemia em março de $2020^{(1)}$.

Esta pandemia modificou o cenário mundial de forma profunda e rapidamente se tornou uma emergência de 
saúde pública, com mais de 3 milhões de casos e 250.687 mil mortes confirmadas pelo mundo até o momento - dados obtidos em $04 / 05 / 2020$ as $18: 32 \mathrm{~h}^{(2)}$. No Brasil, os números giram em torno de 105 mil casos confirmados e 7.288 óbitos e uma taxa de letalidade de 7,0\%. A região Sudeste é a mais afetada, com cerca de 49 mil casos, o que representa $46,9 \%$ dos números totais do país - dados capturados em 04/05/2020 às $16: 30 \mathrm{~h}^{(3)}$.

Os coronavírus são parte de um grande grupo de vírus presentes em diversos vertebrados. Na década de 60 , os primeiros coronavírus capazes de infectar pessoas foram identificados e, desde então, sete cepas diferentes são reconhecidas como patógenos humanos: $\mathrm{HCo}-$ V-OC43, HCoV-HKU1, HCoV-229E e $\mathrm{HCoV}-\mathrm{NL63}$, que costumam resultar em afecções respiratórias brandas, o MERS-CoV (Middle East Respiratory Syndrome), e a SARS-CoV e SARS-CoV-2 (Severe Acute Respiratory Syndrome), que podem causar formas graves de infecções respiratórias ${ }^{(1,4)}$.

Diferentes taxas de mortalidade estão associadas às infecções causadas por coronavírus. Dados epidemiológicos indicam letalidade em torno de $10 \%$ quando analisado o SARS-CoV e de até 35\% tratando-se do MERS- $\mathrm{CoV}^{(4,5)}$. As taxas de mortalidade induzidas pela infecção por SARS-CoV-2 ainda são contraditórias e variam muito entre as diversas regiões afetadas, porém uma letalidade de até $27 \%$ em indivíduos com mais de 85 anos foi previamente descrita ${ }^{(6)}$. Embora as três formas mais graves sejam ameaças importantes em potencial, é necessário considerar a evolução clínica que cada subtipo de coronavírus pode induzir. Tal análise individualizada tem o potencial de interferir diretamente no planejamento estratégico das políticas públicas de saúde, bem como na tomada de decisão e condução do cenário que esteja instaurado.

É fundamental que a comunicação entre o poder público, a comunidade científica e a população seja realizada de forma eficaz, clara e atualizada. A produção e disseminação do conhecimento afeta de forma importante o manejo clínico das diversas manifestações da doença e seus agravos. Sobretudo nos tempos atuais, a garantia do amplo acesso às diretrizes de saúde se relaciona diretamente à promoção da assistência de qualidade, bem como assegura maior tranquilidade e confiança para os profissionais que atuam na assistência direta aos pacientes.

Toda a crise decorrente do COVID-19 resultou em uma união da comunidade científica e de profissionais de saúde sem precedentes. Embora seja surpreendente observar uma resposta tão rápida no enfrentamento à pandemia, o imenso volume de dados que foram disponibilizados tão rapidamente pode dificultar, principalmente para os profissionais que atuam na linha de frente, o acesso ao conteúdo necessário para a tomada de decisões clínicas assertivas em tempos de pandemia. Nesse cenário, encontrar informações sobre os protocolos e testes diagnósticos que orientem tais profissionais pode ser tarefa árdua, sobretudo para os que atuam diretamente no esforço de contenção da doença e já se encontram sobrecarregados com a elevada carga de trabalho. Dessa forma, este estudo propõe-se a expor brevemente algumas informações sobre os testes para COVID-19 atualmente disponíveis no Brasil, bem como algumas recomendações quanto ao seu uso, as quais serão discutidas a seguir.

\section{Exames Diagnósticos e Orientações}

No Brasil, o número de testes rápidos aprovados pela Anvisa vem crescendo rapidamente. A aprovação dos testes para diagnóstico da COVID-19 segue a resolução RDC n. ${ }^{\circ} 348$, de março de 2020, que define critérios e procedimentos temporários e extraordinários em virtude de uma emergência de saúde pública $^{(7)}$.

O método diagnóstico padrão-ouro é o RT-PCR em tempo real utilizan- do amostras que podem ser obtidas de três maneiras diferentes: aspirado nasofaríngeo (ANF), swab combinado (nasal/oral) e secreção respiratória inferior (escarro, lavado traqueal ou lavado bronco alveolar). A coleta do material deve ser realizada até 10 dias após o surgimento dos primeiros sintomas (preferencialmente entre o $3^{\circ}$ e o $5^{\circ}$ dias) por profissionais devidamente paramentados e treinados para a realização do procedimento. A refrigeração das amostras $\left(4-8^{\circ} \mathrm{C}\right)$ é essencial, e estas devem ser analisadas entre 24-72 horas após a coleta. Caso não seja possível o envio da amostra dentro do prazo estabelecido, recomenda-se que o material fique armazenado a $-70^{\circ} \mathrm{C}$ até que o envio seja providenciado. Vale ressaltar que amostras danificadas, com pouco material biológico ou manipuladas/armazenadas incorretamente, bem como amostras coletadas precocemente (com menos de 3 dias do surgimento dos sintomas) ou tardiamente (com mais de 10 dias do surgimento dos mesmos) podem acusar resultado falso negativo de indivíduos contaminados ${ }^{(8)}$. Percebe-se que muitos fatores podem interferir na eficácia e resultado do teste. Deste modo, faz-se imprescindível que os profissionais envolvidos estejam atentos e sigam rigorosamente o protocolo sugerido, a fim de garantir a confiabilidade dos resultados e evitar ao máximo o desperdício de um recurso que tem se mostrado escasso.

O diagnóstico da COVID-19 também pode ser realizado por métodos sorológicos. No Brasil, apenas o ensaio imunocromatográfico para detecção rápida e qualitativa de anticorpos IgG/ IgM da SARS-CoV-2 está disponível, realizado a partir de amostra de sangue total, soro ou plasma humano. A amostra para o teste imunológico deve ser obtida, de forma geral, a partir do $8^{\circ}$ dia do início dos sintomas, assegurando o tempo necessário para que o sistema imunológico produza anticorpos em quantidade suficiente para detecção no teste $^{(8)}$. Este método apresenta a vanta- 
gem de disponibilizar um resultado rápido, porém, devido ao risco de falsos negativos, deve ser empregado apenas para triagem e auxílio diagnóstico, deixando a interpretação a cargo de um médico que disponha de dados complementares clínicos e laboratoriais. O teste sorológico com resultado positivo não deve ser utilizado como único indicador da presença da infecção, bem como um resultado negativo não exclui a possibilidade de o paciente estar infectado. Esta informação é de grande importância, uma vez que resultados falsos negativos podem induzir um indivíduo contaminado a deixar o isolamento domiciliar erroneamente, resultando na disseminação do vírus. Tal possibilidade ilustra a relevância tanto do uso de outros métodos quanto da cautela na interpretação dos resultados ${ }^{(8)}$.

Exames de imagem, os quais devem ser realizados seguindo as medidas necessárias de prevenção e controle de contágio, também são importantes aliados no diagnóstico desta doença, em virtude da agilidade de realização e obtenção dos resultados. A radiografia de tórax é recomendada para todos os pacientes com suspeita de pneumonia e em geral observam-se infiltrados pulmonares unilaterais (25\% dos pacientes) e bilaterais (75\% dos pacientes) nas imagens. A tomografia computadorizada (TC) do tórax é indicada para pacientes com comprometimento do trato respiratório inferior, áreas lobulares e subsegmentares bilaterais de aspecto em vidro fosco costumam estar presentes na maioria dos acometidos pela doença. Vale ressaltar que os indícios da presença de uma pneumonia viral na TC podem estar presentes antes de um RT-PCR positivo para SARS-CoV-2. Pacientes assintomáticos podem apresentar exames de imagem alterados, assim como indivíduos podem testar positivo mesmo sem a presença de achados significativos na tomografia computadorizada ${ }^{(7)}$. Assim como os testes sorológicos, os exames de imagem devem ser utilizados como um método auxiliar, não sendo possível confirmar a presença da infecção por COVID-19 apenas com TC e/ou radiografia de tórax. Vale enfatizar que, durante a realização dos exames, os pro- tocolos que previnem a transmissão de doenças durante o procedimento devem ser seguidos.

Percebe-se que os testes diagnósticos apresentam diferentes vantagens e desvantagens. O teste sorológico e os exames de imagem são de rápida realização e emissão de resultados; podem acusar, porém, falsos negativos e não devem ser utilizados isoladamente no diagnóstico. O RT-PCR é o ideal, no entanto a coleta, manuseio e armazenamento das amostras devem ser fiscalizados e seguir padrões estritos para garantir resultados confiáveis; o elevado tempo de espera também é um fator limitante deste método. Faz-se vital frisar que a indicação, uso e interpretação de cada teste diagnóstico devem ser realizados com cautela e seguindo as orientações e normas estabelecidas. Somente testes aprovados e registrados pela Anvisa devem ser adquiridos e usados conforme a instrução de cada fabricante. Como observado, todos os testes possuem limitações, e devem ser utilizados em conjunto, de forma que todo o seu potencial seja aproveitado. -

\section{REFERÊNCIAS}

1. Góes LGB, Zerbinati RM, Tateno AF, Souza AV, Ebach F, Corman VM, et al. Typical epidemiology of respiratory vírus infections in a Brazilian slum. Journal Med Virol. [Internet]. 2019; 1-6. DOI: 10.1002/jmv.25636.

2. Johns Hopkins Whiting School of Engineering. Center for Systems Science and Engineering [Internet]. Coronavirus COVID-19 Global Cases. 2020 [cited 2020 Apr 28]. Disponível em: https://gisanddata.maps.arcgis com/apps/opsdashboard/index.html\#/bda7594740fd40299423467b48e9ecf6.

3. Ministério da saúde (BR). Painel de casos de doença pelo coronavírus 2019 (COVID-19) no Brasil pelo Ministério da Saúde [Internet]. 2020 [Acesso em 28 abr 2020]. Disponível em: https://covid.saude.gov.br/.

4. Chen Y, Liu Q, Guo D. Emerging coronaviruses: Genome structure, replication, and pathogenesis. J Med Virol. [Internet]. 2020; 92(4):418-423. DOl: https://dx.doi. org/10.1002/jmv.25681.

5. Peeri NC, Shrestha N, Rahman S, Zaki R, Tan Z, Bibi S, et al. The SARS, MERS, and novel coronavirus (COVID-19) epi- demics, the newest and biggest global health threats: what lessons have we learned? Int J Epidemiol [Internet]. 2020; 1-10. DOI: https://doi.org/10.1093/ije/dyaa033.

6. Centers for Disease Control and Prevention (CDC). Severe Outcomes Among Patients with Coronavirus Disease 2019 (COVID-19) — United States, February 12-March 16, 2020. MMWR Morb Mortal Wkly Rep [Internet]. 2020; 69: 343346. DOI: http://dx.doi.org/10.15585/mmwr.mm6912e2.

7. Ministério da Saúde (BR). Diretrizes para Diagnóstico e tratamento da COVID-19. 3 ed [Internet]. Brasília (DF); 2020 [acesso em 26 abr 2020]. Disponivel em: https://portalarquivos.saude.gov.br/images/pdf/2020/April/18/Diretrizes-Covid19.pdf.

8. Ministério da Saúde (BR). Guia de Vigilância Epidemiológica. Emergência de Saúde Pública de Importância Nacional pela Doença pelo Coronavírus 2019. Vigilância Integrada de Síndromes Respiratórias Agudas. Doença pelo Coronavírus 2019, Influenza e outros vírus respiratórios [Internet]. Brasília (DF): MS, 2020 [acesso em 26 abr 2020]. Disponível em: https://www.saude.gov.br/images/pdf/2020/April/06/ GuiaDeVigiEp-final.pdf. 